\title{
Claudicação e acrocianose dos membros superiores en mulher de 56 anos
}

\author{
Claudication and acrocyanosis of the upper limbs in women 56 years
}

A arterite de Takayasu (AT) é uma vasculite de grandes vasos crónica, rara e de etiopatogenia indeterminada, que afeta predominantemente a aorta, seus ramos principais e as artérias pulmonares, verificando-se a existência de estenoses segmentares, oclusões, dilatações ou formações aneurismáticas, sendo mais frequente nas mulheres em idade fértil. 0 diagnóstico precoce requer um elevado índice de suspeição clínica, pois os sintomas iniciais são inespecíficos: astenia, perda ponderal, artralgias ou febre. Numa fase mais avançada, em relação com a fibrose e oclusão, surgem outras manifestações tais como: diminuição da amplitude ou ausência dos pulsos, sopros diferenças de pressão arterial (PA) nos membros superiores, parestesias ou claudicaçã $0^{1,2}$.

Apresentamos o caso de uma mulher de 56 anos, caucasiana, referenciada à consulta por quadro de astenia, artralgias generalizadas, claudicação e acrocianose dos membros superiores com cerca de 1 ano de evolução. Antecedentes pessoais e familiares irrelevantes. Ao exame objetivo salientava-se: PA imensurável em ambos os membros superiores, $159 / 80 \mathrm{mmHg}$ no membro inferior direito e 157/81 mmHg no membro inferior esquerdo; pulsos radiais e braquiais não palpáveis, pulsos dos membros inferiores palpáveis, simétricos e com amplitude normal; acrocianose em ambas as mãos. Do estudo analítico constatou-se anemia normocítica normocrómica ( $\mathrm{Hb} 10,2 \mathrm{~g} / \mathrm{dL})$, velocidade de sedimentação de $64 \mathrm{~mm}$ na $1^{\text {a }}$ hora e proteína $\mathrm{C}$ reativa de $45 \mathrm{mg} / \mathrm{L}$. Realizou angiografia por tomografia computorizada dos troncos supra aórticos e membros superiores, que evidenciou espessamento da parede da artéria aorta, estenoses múltiplas das carótidas externas e oclusão em ambas as subclávias, aspetos compatíveis com arterite de Takayasu (Figuras 1 e 2).

Estabelecido o diagnóstico, foi instituída corticoterapia (prednisolona $1 \mathrm{mg} / \mathrm{Kg} / \mathrm{dia}$ ) e metotrexato $15 \mathrm{mg}$, com melhoria clínica.

\section{Bibliografia}

1. Kerr GS, Hallahan CW, Giordano J, Leavitt RY, Fauci AS, Rottem M, Hoffman GS. Takayasu arteritis. Ann Intern Med. 1994; 120(11): 919-29.

2. Terao C, Yoshifuji H, Mimori T. Recent advances in Takayasu arteritis. Int J Rheum Dis. 2014; 17(3):238-47.

\section{Diagnóstico: Arterite de Takayasu}

\section{Paula Paiva, Alexandre Louro}

Serviço de Medicina Interna.

Unidade Local de Saúde do Norte Alentejano. Portalegre. Portugal.
Figura 1. Angio TC dos troncos supra aórticos e membros superiores: oclusão da artéria subclávia direita no plano da fossa supraclavicular, reabitando focalmente a nível umeral no plano da diáfise proximal.

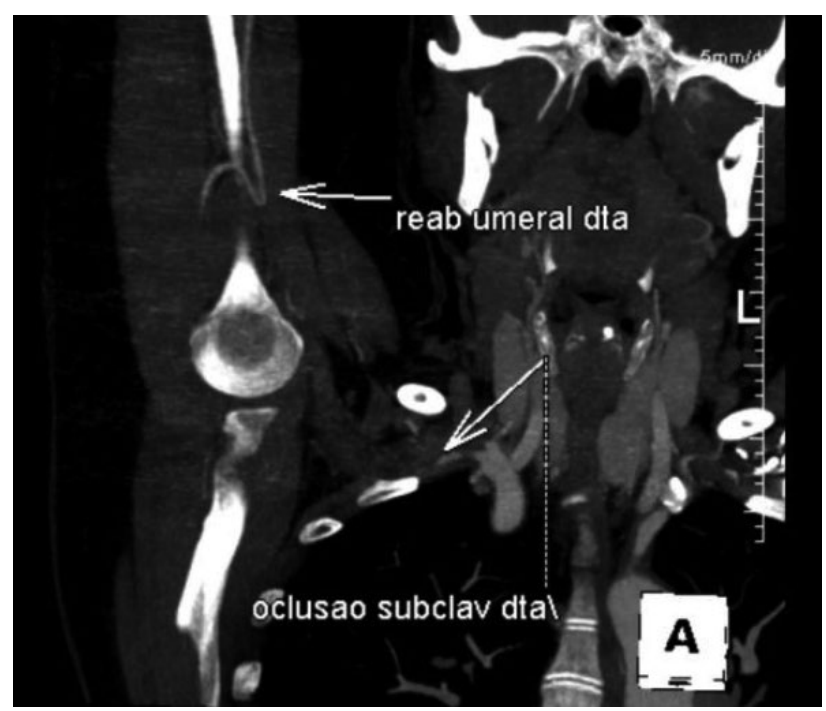

Figura 2. Angio TC dos troncos supra aórticos e membros superiores: oclusão da artéria subclávia esquerda, logo após a emergência da artéria vertebral, com reabitação umeral, num plano semelhante ao evidente à direita.

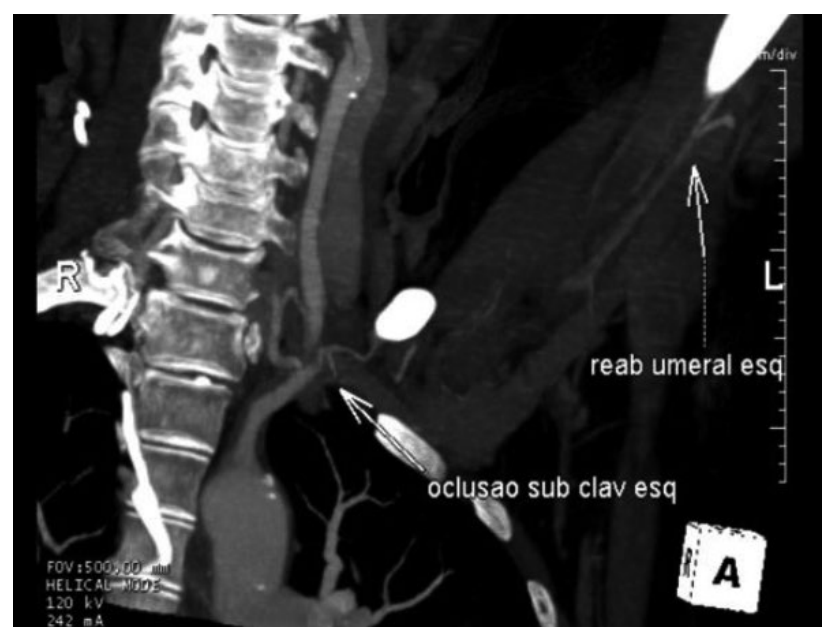

